\title{
Binaural summation after learning psychophysical functions for loudness
}

\author{
LAWRENCE E. MARKS \\ John B. Pierce Laboratory and Yale University, New Haven, Connecticut \\ EUGENE GALANTER \\ Columbia University, New York, New York \\ and \\ JOHN C. BAIRD \\ Dartmouth College, Hanover, New Hampshire
}

\begin{abstract}
Do response-related processes affect perceptual processes? Sometimes they may: Algom and Marks (1990) produced different loudness exponents by manipulating stimulus range, and thereby also modified the rules of loudness summation determined by magnitude scaling. The present study manipulated exponents by having a dozen subjects learn prescribed power functions with exponents of $0.3,0.6$, or 1.2 (re sound pressure). Subjects gave magnitude estimates of the loudness of binaural signals during training, and of monaural and binaural signals after training. During training, subjects' responses followed the nominal functions reasonably well. Immediately following training, subjects applied the numeric response scales uniformly to binaural and monaural signals alike; the implicit monaural-binaural loudness matches, and thus the basic rules underlying binaural summation, were unaffected by the exponent learned. Comparison of these results with those of Algom and Marks leads us to conclude that changing stimulus range likely influences underlying perceptual events, whereas "calibrating" a loudness scale through pretraining leaves the perceptual processes unaffected.
\end{abstract}

Do numerical response scales - for example, the scales that subjects use when they give magnitude estimatesaffect underlying perceptual processes? It is tempting to assume that perceptual processes and numerical decisions are independent, that the magnitudes of underlying perceptual experiences are unaffected by the particular rules by which subjects map these experiences to numerical responses. If perceptual and judgmental processes are independent, the numerical scale should not affect the rank ordering, or the equalities, within the set of underlying perceptual magnitudes. Given this perspective, the results of Algom and Marks (1990) are surprising, and they provide a main motivation for the present study.

Algom and Marks (1990) sought to change their subjects' numeric response scales by manipulating either the range of stimuli (small vs. large) or the psychophysical scaling method (magnitude estimation vs. magnitude production), within the framework of loudnesssummation paradigms: Subjects judged the loudness of one-component tones (presented to just one ear or at one

This research was supported by Grant DC00271 from the National Institutes of Health to the first author. We thank Patricia O'Neill for her assistance, and Joseph C. Stevens for comments on an early version of the article. Bruce Schneider, Martha Teghtsoonian, and an anonymous referee provided valuable critiques. Please direct correspondence to L. E. Marks, John B. Pierce Laboratory, 290 Congress Avenue, New Haven, CT 06519 (e-mail: marks@yalevm.cis.yale.edu). sound frequency) and two-component tones (presented to both ears or simultaneously at two frequencies). Unexpectedly, when different stimulus ranges or scaling procedures did modify the response scale (signified by the exponent of the power function for loudness), the rank ordering of the judgments (signified by matching SPLs) also changed systematically. For example, in Experiment $1 \mathrm{~B}$ of that study, a binaural tone of $56 \mathrm{~dB} \mathrm{SPL}$ was judged as loud as a monaural tone of about $67 \mathrm{~dB}$ when the stimulus range was large and the exponent was small, but as loud as a monaural tone of about $64 \mathrm{~dB}$ when the range was small and the exponent large.

Given these results, Algom and Marks (1990) inferred that the changes in stimulus range (or in scaling procedure, which indirectly affected the range of stimuli) acted to modify the underlying psychophysical transformation of stimulus intensity to loudness, the rule of loudness summation, or both. In particular, Algom and Marks suggested that range-induced shifts in response scale may reflect changes in the "gain" of the auditory system (cf. Parker \& Schneider, 1994; Schneider \& Parker, 1990).

A graphic example may be helpful. Figure 1 shows hypothetical functions relating numerical response $\mathrm{R}$ to stimulus intensity $I$, under conditions that we designate as $\mathrm{A}$ and $\mathrm{B}$. These could correspond to loudness functions under binaural and monaural listening. Three characteristics of these functions are noteworthy. First, using the response scale on the left-hand ordinate, both $\mathrm{A}$ and $B$ are power functions with identical exponents of 0.3 in 


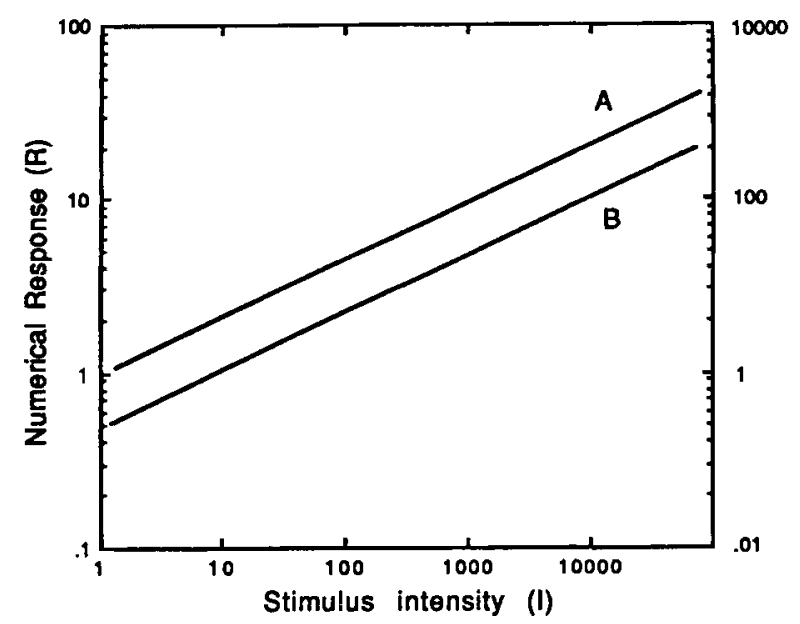

Figure 1. Hypothetical functions relating numerical responses, $R$, to stimulus intensity, I, under two stimulus conditions, $A$ and $B$. With both $A$ and $B$, responses increase as the 0.3 power of intensity (lefthand ordinate) or as the 0.6 power of intensity (right-hand ordinate). At a given intensity level, the ratio of $A: B$ is a constant 2:1 (left ordinate) or 4:1 (right ordinate).

terms of stimulus intensity (corresponding to values of 0.6 were the stimulus reckoned as sound pressure). Second, at any given level of the signal, function $\mathrm{A}$ lies above $\mathrm{B}$, much as loudness judgments given to binaural signals exceed those given to monaural signals. The ratio of $A$ to $B$ is a constant $2: 1$. Third, given that functions $B$ and $A$ are parallel and displaced vertically, they are also displaced horizontally by a constant stimulus ratio-in the present example, an intensity ratio of $10: 1$, or 10 decibels $(\mathrm{dB})$. That is, to produce the same numerical response-and, presumably, equal underlying perceptual magnitudes - the signal intensity in condition $B$ must be $10 \mathrm{~dB}$ greater than that in condition $\mathrm{A}$.

Now, consider what would happen if, first, the subjects in this example were induced to change their response scale, say, by changing stimulus range, and, second, the change in scale consisted simply of a remapping of numerical responses from $R$ to a new scale, $R^{\prime}$, nonlinearly related to $R$. Let us assume that $R^{\prime}=R^{2}$. To show the outcome, it is not even necessary to redraw the functions in Figure 1, but merely to relabel the values on the ordinate. The numerical scale corresponding to $R^{\prime}$ is given on the right-hand ordinate. Note that the change in response scale entails an equivalent change in the vertical separation between $A$ and $B$. The 2:1 ratio of $A: B$ characterizing scale $R$ becomes $2^{2}: 1=4: 1$ ratio characterizing $R^{\prime}$. But changing the scale in this way leaves the horizontal separation unaffected; that is, it still takes a tenfold greater stimulus intensity in condition B than in condition $\mathrm{A}$ to produce the same perceptual response. Finally, we note that changes in response scale need not involve a power transformation. Given any continuous, monotonically increasing transformation of response scale $R$, we can relabel values on the ordinate and leave intact the horizontal separation between functions A and $B$.

If the two parallel functions of Figure 1 represent binaural and monaural loudness, then the vertical separation reflects the binaural ratio (a constant that describes the relation between binaural and monaural loudness at a given signal intensity), whereas the horizontal separation reflects the binaural gain (the difference in $\mathrm{dB}$ between matching monaural and binaural signals). In several experiments, Algom and Marks (1990) discovered that, when the exponent of the power functions for monaural and binaural loudness shifted-either by manipulating stimulus range directly in magnitude estimation, or, manipulating range indirectly, by changing the method from magnitude estimation to magnitude productionthe binaural ratio remained approximately constant, but the binaural gain changed. This outcome is surprising if we assume that manipulating range or method produces only a uniform change in the way subjects express relative loudness numerically - the model depicted by Figure 1-and it led Algom and Marks to hypothesize that their manipulations affected not only the exponents but also the underlying perceptual processes of loudness summation.

There is, however, another possible explanation: It is conceivable that manipulations of stimulus range do affect only response processes, but in a stimulus-specific fashion. Let us give an example. Consider a binauralsummation paradigm, in which subjects give magnitude estimates to a series of tones, some presented monaurally and some binaurally. Assume that, given a particular stimulus range, and so forth, the subjects produce functions for monaural and binaural listening like $A$ and $\mathrm{B}$, respectively, in Figure 1. The exponent is 0.6 (re sound pressure), and the numbers assigned to binaural signals are twice those assigned to equally intense monaural signals. Now, we change the set of conditions, perhaps by contracting the stimulus range. Both binaural and monaural exponents may increase; but if the subjects maintain a tendency to judge the loudness of binaural signals as twice monaural signals, then the binaural ratio will not change: As the slopes increase but the vertical separation between the loudness functions remains the same, the horizontal separation-binaural gain, in $\mathrm{dB}$ - must decline, much as Algom and Marks (1990) found. According to this account, therefore, the change in binaural gain has nothing directly to do with changes in stimulus range per se, except insofar as changes in range induce changes in exponent. Instead, the change in binaural gain reflects a failure to assign equal numerical responses to equally loud binaural and monaural signals under transformation of the response scale.

In the present study, we sought to test one version of this explanation by teaching subjects to judge the loudness of binaural signals according to different, predetermined intensity-response functions using a constant stimulus range, then testing for generalization to monaural as well as binaural signals. If subjects tend to main- 
tain a constant binaural ratio in the face of changing exponents, the binaural gain should decrease as the exponent increases. If, on the other hand, the changes in binaural gain observed by Algom and Marks (1990) reflect changes in perceptual processing wrought by changes in stimulus range per se, the binaural gain should remain constant, independent of the overt response scales that the subject learns.

How well can subjects learn different magnitude scales? Koh and Meyer (1991; see also Koh, 1993) taught subjects different quantitative rules, including both linear functions and power functions relating responses (durations between taps) to stimuli (visual lengths). King and Lockhead (1981) showed that subjects can readily learn to give magnitude estimates of loudness that follow power functions of sound pressure with exponents of 0.33 , 0.67 , and 1.0. None of these studies asked how changing the response scale might affect such perceptual processes as intensity summation.

Taking a related tack, Ward (1992) suggested that psychophysical scaling studies be conducted only after subjects have been trained to produce a predefined function. Presumably, once subjects have all learned, for example, to judge loudness by a 0.6 power of sound pressure (S. S. Stevens's, 1956, sone function), it would be possible to study various phenomena of psychoacoustics (e.g., masking, temporal interactions) and judgment (effects of stimulus range, effects of stimulus sequence) with a known stimulus-response function, thereby minimizing interindividual differences (cf. Galanter, 1988; Galanter $\&$ Wiegand, 1991). Following this line, West and Ward (1994) taught subjects to give magnitude estimates of $1000-\mathrm{Hz}$ tones that followed a 0.6 power of sound pressure; subsequent judgments of signals at lower and higher sound frequencies differed from those at $1000 \mathrm{~Hz}$ as one might predict from equal-loudness contours. As in other earlier studies, West and Ward did not ask whether teaching different response scales might exert differential effects. In the present experiment, we systematically manipulated the exponent governing the relation between numerical responses and binaural signal levels in the training sessions, in order to determine whether subsequent judgments of monaural and binaural signals would undergo corresponding changes (e.g., in binaural gain) that would signify modifications in underlying perceptual processing.

\section{METHOD}

\section{Stimuli}

Signals were produced and shaped by Coulbourn Systems modules, under the control of an Apple IIe computer, which also collected the data through a numeric keypad. All signals were $500-\mathrm{Hz}$ sinusoids, with $10-\mathrm{msec}$ rise/fall and $1-\mathrm{sec}$ duration, presented through calibrated TDH-49 headphones. Each experimental session comprised two parts, a training period followed by a test period. In the training period, all signals were presented binaurally, at 21 SPLs that varied from 35 to $75 \mathrm{~dB}$ in 2-dB steps; in the test period, one third of the signals were presented binaurally, at 11 SPLs that varied from 35 to $75 \mathrm{~dB}$ in $5-\mathrm{dB}$ steps, and the remaining two thirds were presented monaurally, 11
SPLs each to the left and right ears, from 45 to $85 \mathrm{~dB}$. Note that monaural SPLs were augmented above binaural ones, following the procedure of Algom and Marks (1990), in order to make the overall levels of monaural and binaural loudness similar.

\section{Procedure}

During training, subjects heard all 21 signals presented in four randomly ordered replicates. Subjects were told that their task was to learn the loudness scale used by another (imaginary) person. After every magnitude estimate they would receive visual feedback (on the computer's monitor) telling them what response the person would have made. The response scales were defined by power functions with exponents of $0.3,0.6$, and 1.2 re sound pressure. All numbers provided in the feedback period were integer values. Moreover, all three power functions were generated to produce a value of " 100 " at an SPL of $55 \mathrm{~dB}$; this constraint ensured that all numbers provided as feedback would exceed unity.

Once the training period was completed, the binaural-summation paradigm (test period) began immediately, with the 33 different signals presented in 8 randomly ordered replicates. Feedback was discontinued, and the subjects were asked to use the scale that they had just learned. in order to judge the loudness of each subsequent tone.

Twelve young men and women with normal hearing served in three sessions, defined by the predetermined exponents 0.3 (Condition $\mathrm{A}$ ), 0.6 (Condition $\mathrm{B}$ ), and 1.2 (Condition $\mathrm{C}$ ), conducted on different days. Order of conditions was counterbalanced over subjects.

\section{RESULTS AND DISCUSSION}

\section{Loudness Functions During Training}

Figure 2 shows the magnitude estimates given in the three training periods, pooled geometrically within and across subjects. The line drawn through each set of points indicates the nominal function (feedback) provided to the subjects. As Figure 2 makes clear, subjects on the whole did reasonably well in learning these response scales. Exponents (slopes of the log-log functions) as determined by method of least squares were

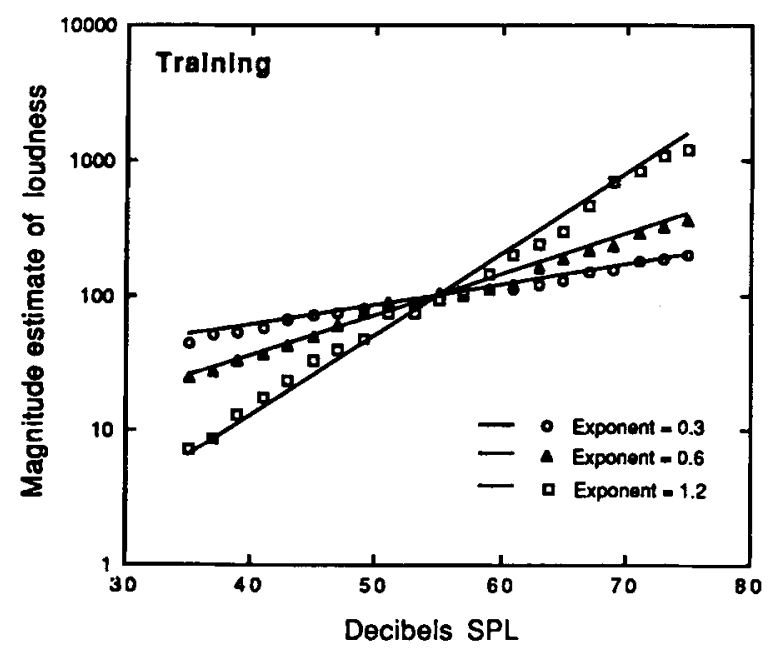

Figure 2. Geometric mean magnitude estimates of loudness obtained while subjects learned psychophysical functions for loudness with various exponents. 
$0.31,0.58$, and 1.11 in Conditions $\mathrm{A}, \mathrm{B}$, and $\mathrm{C}$, respectively-close to the nominal values of $0.30,0.60$, and 1.20. Only in Condition $\mathrm{C}$ did the observed exponent differ reliably from the nominal value $[t(11)=2.34, p<$ $.05]$.

Figure 3 breaks down these averages to show judgments in the first two blocks of trials (replicates) versus the second two blocks. In particular, when learning the two smaller exponents, the subjects initially produced slightly steeper functions (greater exponents), after which responses stabilized. It follows that exponents determined after responses stabilized are a little smaller than exponents determined by pooling the data over all four blocks. Still, these differences are relatively minor. Exponents in the second half of the training periods were $0.28,0.53$, and 1.08 ; they were $0.34,0.62$, and 1.14 in the first half. Analysis of variance (ANOVA) conducted with the three training conditions as one variable and the two halves of the training period as the second variable confirmed that exponents were significantly smaller in the second half $[F(1,11)=18.0, p<.002]$; post hoc tests showed the decline to be reliable in Conditions $\mathrm{A}$ $[F(1,11)=26.6, p<.001]$ and $\mathrm{B}[F(1,11)=17.2, p<$ $.0025]$, though not in Condition $\mathrm{C}[F(1,11)=3.25, p<$ $.10]$. Like Figure 2, Figure 3 reveals how the judgments deviate systematically from the nominal functions used in training. In particular, when the subjects tried to learn an exponent of 1.2 , the loudness functions are sinuous. Subjects underestimated the loudness of signals just below the middle of the scale and overestimated ones just above it - a consequence, no doubt, of placing heavy reliance on the center and end points of the scale.

\section{Individual Variation During Training}

Although every subject received feedback based on exactly the same function in each condition, individuals nevertheless showed variation during training. Individ-

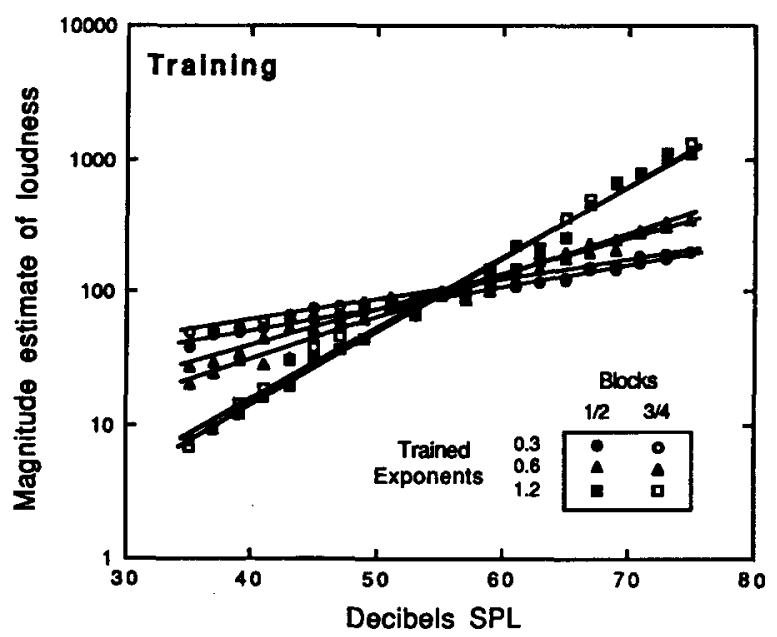

Figure 3. The magnitude estimates of Figure 2 broken down into results obtained in Blocks 1 and 2 (filled symbols) and Blocks 3 and 4 (open symbols). ual differences are known to abound in magnitude scaling, exponents often varying from one person to another by a factor of two or three (see, e.g., J. C. Stevens \& Guirao, 1964). Even here, while subjects were learning fixed and uniform response scales, individual exponents (based on responses given in the last two blocks of trials) nevertheless did fluctuate a bit - the ratio of the highest to lowest exponent increasing to $1.60: 1$ when subjects tried to learn an exponent of 1.2 ; the ratios were 1.27:1 and 1.38:1 when subjects tried to learn exponents of 0.3 and 0.6 .

The standard deviations of the exponents (data from Blocks 3 and 4) were $0.019,0.032$, and 0.119 in Conditions $\mathrm{A}, \mathrm{B}$, and $\mathrm{C}$, respectively; the ratio of the standard deviation to the mean exponent varied from 0.068 in Condition A to 0.060 in $\mathrm{B}$ to 0.110 in $\mathrm{C}$. The change in variability across conditions is reliable; Cochran's $\mathrm{C}$, calculated on $\log$ individual exponents, equals $0.62(p<$ .05 ). This outcome may stem from the particular difficulty that subjects seemed to face when they sought to learn an exceptionally large power-function exponent. In a related study, Baird, Kreindler, and Jones (1971) had subjects judge line length and provided the subjects with numeric values to the smallest and largest stimuli that defined different power-function exponents; under these conditions, subjects had greater difficulty in producing power functions with large exponents $(>1)$ than in producing power functions with small ones $(<1)$.

\section{After Training}

Immediately after training, feedback was discontinued and the subjects gave magnitude estimates of loudness in a binaural-summation paradigm. Figure 4 shows the results, giving data from each condition in a separate panel (recall that in posttraining, the monaural SPLs were $10 \mathrm{~dB}$ greater than the binaural SPLs). Note, first, that in all three cases the exponents dropped once the feedback stopped. In Condition A (nominal exponent of 0.3 ), the binaural and monaural exponents were 0.24 and 0.25 , respectively (vs. 0.28 for the last two blocks of training); in B, they were 0.44 and 0.45 (vs. 0.53); and in $\mathrm{C}$, they were 0.95 and 0.89 (vs. 1.08). The decline in (directly comparable binaural) exponents was reliable both overall $[F(1,22)=30.6, p<.0005]$, according to ANOVA, and separately in Conditions $\mathrm{B}(p<.05)$ and $\mathrm{C}(p<.01)$, though not in Condition A, by Tukey's HSD, or honest significant difference. The same statistical conclusions hold for average binaural and monaural exponents after training.

\section{Binaural Summation}

From a theoretical perspective, the most important aspect of the results, evident in Figure 5, is the displacement of the three pairs of monaural and binaural loudness functions. This displacement may be calculated in two ways: (1) as a difference in $(\log )$ values on the ordinate - that is, as a difference in the numerical judgments given at constant SPL - and (2) as a difference in the $(\log )$ values on the abscissa-that is, as a difference in 

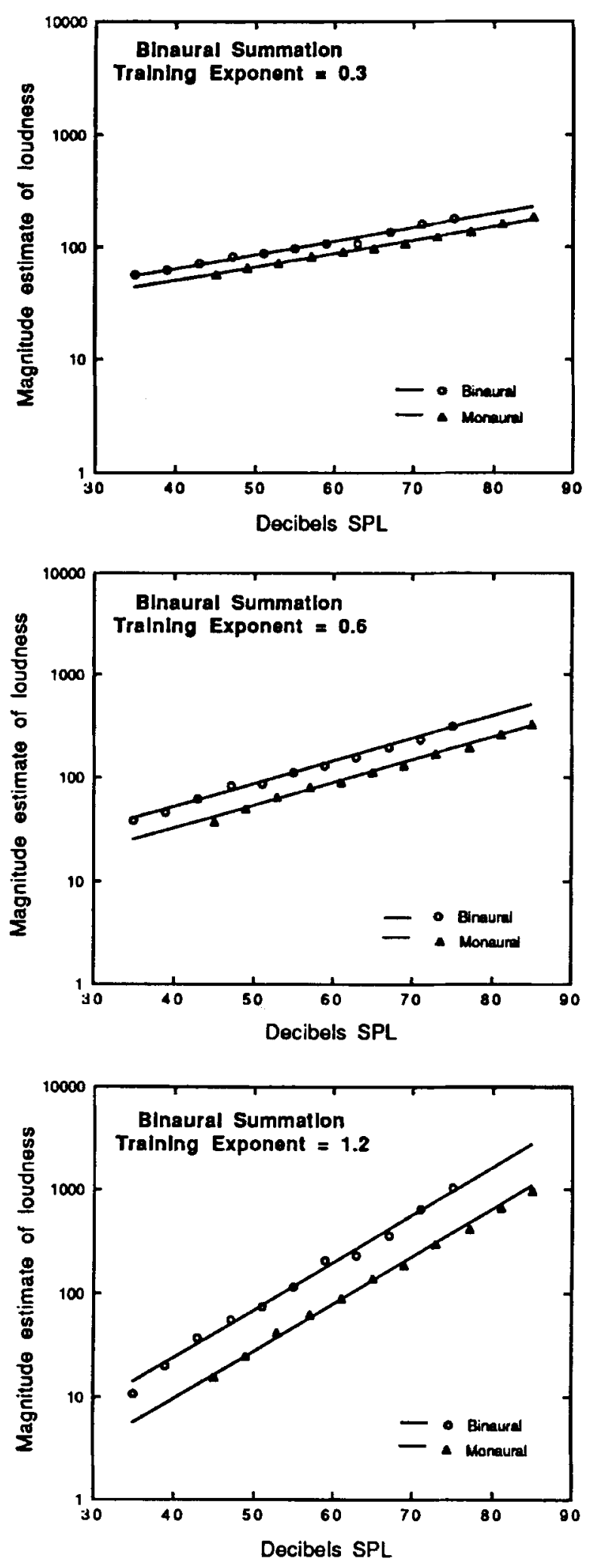

Figure 4. Magnitude estimates of loudness obtained in the binaural-summation paradigm, which immediately followed training with the various exponents (given in different panels). the $\mathrm{dB}$ levels at a constant level of judged loudness. The first measure of displacement corresponds to the binaural summation ratio, $\mathrm{BR}$; the second measure corresponds to the binaural gain, BG. Given that the judgments of loudness of binaural signals, $R_{b}$, and monaural signals, $R_{m}$, can be described as power functions of sound pressure $\mathbf{P}$, with equivalent exponents, $\gamma$, within each condition,

$$
\begin{aligned}
& \mathrm{R}_{\mathrm{b}}=\mathrm{k}_{\mathrm{b}} \mathrm{P}_{\mathrm{b}}^{\gamma}, \\
& \mathrm{R}_{\mathrm{m}}=\mathrm{k}_{\mathrm{m}} \mathrm{P}_{\mathrm{m}}^{\gamma},
\end{aligned}
$$

then, by definition, the binaural summation ratio, $\mathrm{BR}=$ $\mathrm{R}_{\mathrm{b}} / \mathrm{R}_{\mathrm{m}}=\mathrm{k}_{\mathrm{b}} / \mathrm{k}_{\mathrm{m}}$, and the binaural gain in decibels, $B \mathrm{G}=$ $20 \log \left(\mathrm{P}_{\mathrm{m}} / \mathrm{P}_{\mathrm{b}}\right)$.

First, consider the summation ratio. It is clear that the greater the size of the exponent, the greater is the vertical separation, BR, between binaural and monaural functions. This outcome is precisely what we would expect from the model characterized in Figure 1. The average values of $\log B R$ are $0.11,0.21$, and 0.4 , almost perfectly proportional to observed values of $\gamma$. We infer, therefore, that learning exponents of $0.3,0.6$, and 1.2 simply led the subjects to apply three uniform translations of their loudness percepts into numeric responses (even if we do not know the character of the loudness function prior to such translation). That is, we assume that subjects mapped a common set of numbers onto all values of loudness, both binaural, $\mathrm{L}_{b}$, and monaural, $\mathrm{L}_{\mathrm{m}}$. Because measures of the binaural-summation ratio, BR, are related to measures of binural summation in decibels, $\mathrm{BG}$, given a fixed exponent, we provide more explicit tests by computing BG as well as BR in each of the three conditions.

Table 1 gives the values of $\mathrm{dB}$ summation (binaural gain, BG) for all 12 subjects in each condition. Binaural gain corresponds to the horizontal separation between monaural and binaural loudness functions, and is calculated as $20 \log (B R / \gamma)$, using the average value of the monaural and binaural exponents for $\gamma$. BG does not vary systematically with $\gamma$, equaling $9.2,9.4$, and 8.8 in the three conditions. An ANOVA revealed no reliable differences among them $[F(2,22)=0.516, p>$.6]. But, on the average, the binaural ratio (vertical separation) does vary systematically, equaling 1.29:1, 1.62:1, and 2.54:1 in the three conditions. An ANOVA performed on log differences between binaural and monaural intercepts showed the overall differences to be highly reliable $[F(2,22)=70.7, p<.0001]$ (after correcting for nonsphericity in repeated measures). Furthermore, Tukey's HSD shows that each summation ratio differs reliably from both of the others $(p<.01)$.

This outcome contrasts in two important and related ways with the findings of Algom and Marks (1990), who induced changes in exponent by manipulating the range of stimulation--either directly, by presenting the subjects with different $\mathrm{dB}$ ranges in magnitude estimation. 


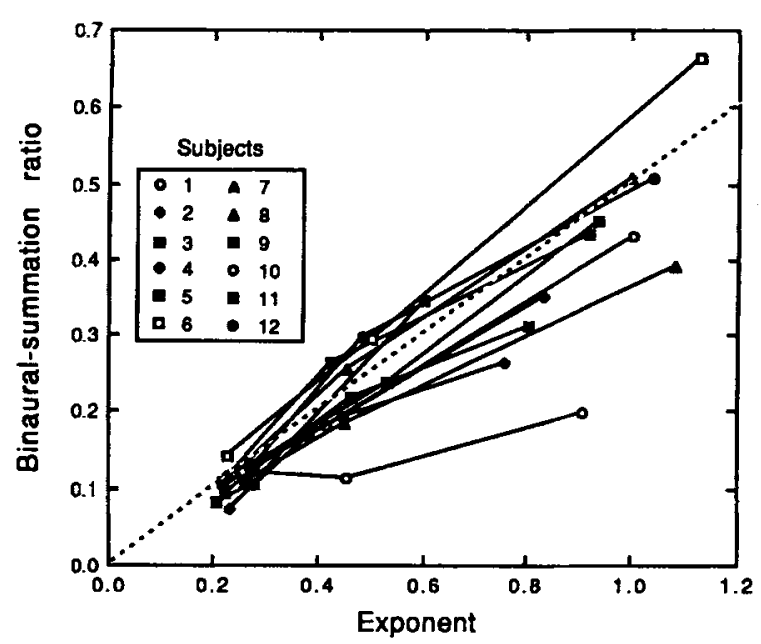

Figure 5. Logarithms of the summation ratios (ratio of binaural to monaural loudness) plotted against exponents, as derived from individual power functions obtained in the binaural-summation paradigm. The dashed line shows the prediction made by assuming that loudness summation is complete (binaural ratio $=2.0$ ) when loudness is measured in sones (exponent $=0.6$ ).

or indirectly, by inducing the subjects to produce smaller $\mathrm{dB}$ ranges in magnitude production than the experimenters presented to the subjects in magnitude estimation. Indeed, Algom and Marks's results are precisely the inverse of the present ones. Whereas here we find the binaural loudness ratio increases with exponent, but $\mathrm{dB}$ summation remains the same, Algom and Marks found that the binaural ratio (BR) remained more or less constant, but $\mathrm{dB}$ summation (BG) decreased systematically. For example, in Experiment $1 \mathrm{~B}$ of their study, cutting the $\mathrm{dB}$ range in magnitude estimation by one half led to virtually no change in binaural ratio, but to roughly a $40 \%$ increase in exponent; consequently, average $\mathrm{dB}$ summation decreased from 9.7 to 8.1 . This means that a monaural tone had to be nearly $10 \mathrm{~dB}$ greater than a binaural tone to appear equally loud when the range of SPLs was large (and the exponent small), but only about $8 \mathrm{~dB}$ greater when the range was small (and the exponent large).

Not so here. Despite the fourfold change in exponent and the doubling of the summation ratio, there was virtually no change in dB summation. Given the clearcut results of Algom and Marks (1990) with relatively modest changes in exponent, it seems unlikely that the constancy of $\mathrm{dB}$ summation in the present study is due to lack of sensitivity of the scaling procedure.

Algom and Marks (1990) offered two hypotheses to explain their results. One was that stimulus range not only affects the rule by which subjects apply numbers to loudness, but also induces subjects to adjust their scales in different ways to monaural and binaural signals; according to this hypothesis, subjects actually use two different rules to map numbers onto loudness, depending on the sound's perceived spatial location, so as to keep the binaural ratio BR constant. The present results speak directly against this hypothesis, however, for our results give no support to the view that impelling subjects to change exponent per se-by teaching a predetermined loudness function-in any way induces them to apply response scales separately to binaural and to monaural signals.

Algom and Marks's (1990) second hypothesis states that changes in stimulus range modify not only numeric response tendencies but also the differential gain within the auditory system (perhaps along the lines of the "differential amplifier" suggested by Schneider \& Parker, 1990 , and Parker \& Schneider, 1994). Our results lead us to infer that no such differential amplification takes place when subjects simply learn different overt loudness exponents. Instead, these results support the contention that the underlying perceptual processes are largely if not wholly independent of the particular exponents that the subjects are trained to produce.

\section{Individual Variation in Loudness Perception and Summation}

Although learning different exponents was not associated with different rules of binaural summation (as inferred from $\mathrm{dB}$ measures), inspection of Table 1 indicates that the subjects did vary somewhat among themselves in the extent of loudness summation. Although most subjects showed as a rule $8-9 \mathrm{~dB}$ of summation, a few, like Subject 6, consistently gave larger values, whereas others, like Subject 10, gave smaller ones.

One particularly informative way to assess individual variation in summation is to see how each subject's log binaural loudness ratio varies as the exponent changes across the training conditions. Perhaps individual differences in exponent reflect nothing but individual differences in overt response scales. If so-if the underlying transformation from sound pressure to loudness and the subsequent rule of binaural loudness addition are uniform over individuals, and individual differences in exponent reflect variations in response scales - then individual variations in exponent should correlate with variations in

Table 1

Measures of Binaural Summation in Decibels, or Binaural Gain, for Each Subject in Each Condition (Feedback Based on Power-Function Exponents of $0.3,0.6$, and 1.2 re Sound Pressure)

\begin{tabular}{crrr}
\hline & \multicolumn{3}{c}{ Exponent Used in Training } \\
\cline { 2 - 4 } Subject & 0.3 & 0.6 & 1.2 \\
\hline 1 & 10.1 & 8.7 & 8.6 \\
2 & 9.1 & 8.6 & 6.9 \\
3 & 9.8 & 12.4 & 9.4 \\
4 & 6.2 & 8.7 & 8.4 \\
5 & 9.5 & 9.0 & 9.6 \\
6 & 12.3 & 11.7 & 11.8 \\
7 & 9.9 & 11.2 & 10.2 \\
8 & 8.2 & 8.1 & 7.2 \\
9 & 8.4 & 9.4 & 7.8 \\
10 & 9.4 & 5.0 & 4.4 \\
11 & 7.8 & 7.5 & 11.5 \\
12 & 9.1 & 12.2 & 9.8 \\
\hline
\end{tabular}


binaural ratio BR. As in the model characterized by Figure $1, \log$ BR should be proportional to the measured exponent $\gamma$ (see Algom \& Marks, 1984, 1990; Marks, 1987). Results of several studies (Algom \& Marks, 1984; Fletcher \& Munson, 1933; Marks, 1978, 1979) are consistent with the simple rule that loudness summation in sones is complete - that is, the ratio of binaural to monaural loudness is $2: 1$ when the exponent equals 0.6 . (But not all results agree; see, e.g., Algom \& Marks, 1990; Scharf \& Fishken, 1970.) Whatever the exact rule of summation, as long as that rule is uniform over individuals, then when every subject's measured log summation ratio is plotted against the measured exponent, the ensemble of points should collapse onto a single straight line.

Figure 5 shows the present results. The dashed line has a slope of 0.5 , constructed under the hypothesis that binaural summation is complete in sones (with an exponent of $0.6, \mathrm{BR}=2.0$, and thus $\log \mathrm{BR}=0.3$ ). But the plot of $\log$ binaural-summation ratio against exponent reveals some distinct differences among individuals. Although in a few cases the points cluster around the dashed line, in agreement with the hypothesis of complete summation in sones, several fall below the dashed line. ${ }^{1}$

Figure 5 suggests that people differ systematically in the exact mathematical rule underlying binaural summation. Perhaps individuals have different underlying loudness functions, perhaps power functions with different exponents. In this regard, we point out that several earlier investigations, carried out with methods such as conjoint scaling of loudness (Levelt, Riemersma, \& Bunt, 1972; Schneider, 1988) and nonmetric scaling of loudness differences (Popper, Parker, \& Galanter, 1986; Schneider, 1980), suggest the presence of substantial interindividual variation in the exact form of the psychophysical function for loudness - that is, real individual differences in exponent. Although we may not be able to ascertain at this point just how loudness functions vary in our subjects, we can be reasonably sure that vary they do. For unlike Algom and Marks's (1990) paradigm, the present method of training exponents appears not to influence the underlying processes by which physical signals are converted to psychological magnitudes and then summed across the ears.

\section{Psychophysical Scaling and Perceptual Matching}

A central issue of this article concerns the independence of underlying perceptual representations from the mechanisms governing the choice of response scales. Independence is often presupposed in scaling studies undertaken to evaluate multivariate sensory processing. For example, in an oft-cited study, J. C. Stevens and S. S. Stevens (1963) used magnitude estimation to determine how the brightness of a flash of light depends jointly on the flash's luminance and the eye's state of adaptation: Direct interocular comparisons of brightness under comparable conditions of light adaptation and dark adaptation served to confirm inferences about the process of adaptation that Stevens and Stevens drew from the magnitude estimates.

J. C. Stevens and S. S. Stevens's (1963) study bore an important implication: that the brightness matches derived indirectly from magnitude estimates did not depend on the particular response scale that their subjects happened to use. Had the subjects used larger or smaller numerical ranges, and thereby produced smaller or greater exponents, the implicit brightness matches would have been the same. That is, the underlying perceptual representations of brightness under different states of adaptation are independent of the choice of response scale.

Yet this view has occasionally been challenged. In a study in which they were concerned mainly with visual reaction times to lights varying in luminance and duration, Raab, Fehrer, and Hershenson (1961) also had subjects rate brightness on a nine-point category scale. The ratings failed to demonstrate a Broca-Sulzer effect (brightness reaching a maximal value at intermediate durations), although direct matching does show this effect. A few years later, Lewis (1965) elaborated these measurements, using an 11-point category scale, and also found no evidence of a Broca-Sulzer maximum. Moreover, Lewis calculated the critical duration for temporal integration of luminous energy and found it to be independent of the luminance level of the light. Both of these outcomes fly in the face of findings obtained both by direct matching (Aiba \& S. S. Stevens, 1964) and by magnitude estimation (Raab, 1962; J. C. Stevens \& Hall, 1966).

Discrepancies have also appeared in hearing. Although J. C. Stevens and Hall (1966) obtained timeintensity reciprocity functions from magnitude estimates that were consistent with functions reported for direct matching, McFadden (1975) reported contrary results: Using magnitude estimation, McFadden derived timeintensity functions that varied substantially among the 4 individuals tested and that deviated markedly from values typically obtained by direct loudness matching. Results such as McFadden's in hearing and Lewis's (1965) in vision have made it at least plausible to question the assumption that numeric response scales always maintain perceptual equalities. Another account might attribute such results to scale-induced changes in perceptual processing, and thus to changes in the perceptual equalities themselves. These two kinds of explanation are analogous to those suggested by Algom and Marks (1990). Although in our opinion there is still no good explanation for the findings reported by McFadden and by Lewis (1965), the present study does imply that substantial shifts in response scale (exponent) per se do not materially affect the processes underlying loudness summation.

\section{REFERENCES}

Aiba, T. S., \& Stevens, S. S. (1964). Relation of brightness to duration under light- and dark-adaptation. Vision Research, 4, 391-401.

Algom, D., \& MARKs, L. E. (1984). Individual differences in loudness processing and loudness scales. Journal of Experimental Psychology: General, 113,57l-593. 
AlgOM, D., \& Marks, L. E. (1990). Range and regression, loudness scales and loudness processing: Toward a context-bound psychophysics. Journal of Experimental Psychology: Human Perception \& Performance, 16, 706-727.

Baird, J. C., Kreindler, M., \& Jones, K. (1971). Generation of multiple ratio scales with a fixed stimulus attribute. Perception \& Psychophysics, 9, 399-403.

Fletcher, H., \& Munson, W. A. (1933). Loudness, its definition, measurement and calculation. Journal of the Acoustical Society of America, 5, 82-108.

GaLANTER, E. (1988). Smooth psychophysical functions from individuals. In H. E. Ross (Ed.), Fechner Day '88: Proceedings of the Fourth Annual Meeting of the International Society for Psychophysics (pp. 41-46). Stirling, Scotland: ISP.

Galanter, E., \& Wiegand, T. E. (1991). Multiple moduli and payoff functions in psychophysical scaling. In S. J. Bolanowski, Jr., \& G. A. Gescheider (Eds.), Ratio scaling of psychological magnitude: In honor of the memory of S. S. Stevens (pp. 129-139). Hillsdale, NJ: Erlbaum.

KING, M. C., \& Lockhead, G. R. (1981). Response scales and sequential effects in judgment. Perception \& Psychophysics, 30, 599-603.

$\mathrm{KoH}, \mathrm{K}$. (1993). Induction of combination rules in two-dimensional function learning. Memory \& Cognition, 21, 573-590.

KoH, K., \& MEYER, D. E. (1991). Function learning: Induction of continuous stimulus-response relations. Journal of Experimental Psychology: Learning, Memory, \& Cognition, 17, 811-836.

Levelt, W. J. M., Riemersma, J. B., \& Bunt, A. A. (1972). Binaural additivity of loudness. British Journal of Mathematical \& Statistical Psychology, 25, 51-68.

LEWIS, M. F. (1965). Category judgments as functions of flash luminance and duration. Journal of the Optical Society of America, 55, 1655-1660.

MARKS, L. E. (1978). Binaural summation of the loudness of pure tones. Journal of the Acoustical Society of America, 64, 107-113.

MARKS, L. E. (1979). A theory of loudness and loudness judgments. Psychological Review, 86, 256-285.

MARKS, L. E. (1987). Binaural versus monaural Joudness: Supersummation of tone partially masked by noise. Journal of the Acoustical Society of America, 81, 122-128.

MCFADDEN, D. (1975). Duration-intensity reciprocity for equal loudness. Journal of the Acoustical Society of America, 57, 702-704.

PARker, S., \& SchneIder, B. (1994). The stimulus range effect: Evidence for top-down control of sensory intensity in audition. Perception \& Psychophysics, 56, 1-11.

Popper, R., PARKER, S., \& Galanter, E. (1986). Dual loudness scales in individual subjects. Journal of Experimental Psychology: Human Perception \& Performance, 12, 61-69.

RAAB, D. H. (1962, January 29). Magnitude estimation of the brightness of brief foveal stimuli. Science, 135, 42-44.

RAAB, D. [H.], Fehrer, E., \& Hershenson, M. (1961). Visual reaction time and the Broca-Sulzer phenomenon. Journal of Experimental Psychology, 61, 193-199.

SCHARF, B., \& FISHKEN, D. (1970). Binaural summation of loudness: Revisited. Journal of Experimental Psychology, 86, 374-379.

SCHNEIDER, B. (1980). Individual loudness functions determined from direct comparisons of loudness intervals. Perception \& Psychophysics, 28, 493-503.

SCHNEIDER, B. (1988). The additivity of loudness across critical bands: A conjoint measurement approach. Perception \& Psychophysics, 43, 211-222.

Schneider, B., \& Parker, S. (1990). Does stimulus context affect loudness or only loudness judgment? Perception \& Psychophysics, 48, 409-418.

Stevens, J. C., \& Guirao, M. (1964), Individual loudness functions. Journal of the Acoustical Society of America, 36, 2210-2213.

Stevens, J. C., \& HaLL, J. W. (1966). Brightness and loudness as functions of stimulus duration. Perception \& Psychophysics, 1, 319-327.

Stevens, J. C., \& Stevens, S. S. (1963). Brightness function: Effects of adaptation. Journal of the Optical Society of America, 53, 375385 .

STEVEnS, S. S. (1956). The direct estimation of sensory magnitudesloudness. American Journal of Psychology, 69, 1-25.

WARD, L. M. (1992). Who knows? In G. Borg \& G. Neely (Eds.), Fechner Day 92: Proceedings of the 8th Annual Meeting of the International Society for Psychophysics (pp. 217-222). Stockholm: ISP.

WEST, R., \& WARD, L. M. (1994). Constrained scaling. In L. M. Ward (Ed.), Fechner Day 94: Proceedings of the 10th Annual Meeting of the International Society for Psychophysics (pp. 225-230). Vancouver, BC: ISP.

\section{NOTE}

1. To the extent that the joint values of $\log \left(R_{b} / R_{m}\right)$ and $y$ entail individual differences in the rules underlying binaural summation, they also entail corresponding differences in $\mathrm{dB}$ summation or $\mathrm{BG}$ (this follows because $B G$ is proportional to the $\log$ summation ratio divided by the exponent [slope]).

(Manuscript received August 23, 1993; revision accepted for publication March 5, 1995.) 